\title{
Publications in inflammatory bowel diseases in the Archives of Gastroenterology
}

Saad-Hossne R. Publications in inflammatory bowel diseases in the Archives of Gastroenterology. Arq Gastroenterol. 2021;58(4):417-8.

A brief historical analysis of inflammatory bowel diseases (IBD) allows us to visualize a new scenario, either in incidence and prevalence, combined with new concepts, new strategies and consequently new challenges, which are more defying in children and adolescents in terms of diagnosis and treatment. As we know, IBD still has no cure and its treatment and control will be permanent, associated with that there is the real necessity for surgical treatment, whether it is due to complications, such as failure of clinical treatment or due to the more aggressive course of the pediatric disease. Likewise, delayed puberty and compromised growth have definite and devastating impacts on this population.

We have observed an increase in the number of publications with international and national data about the epidemiology of IBD. In a deeper and more detailed reading, we observe that in the international scenario, especially in developed countries, there is a certain trend towards the stabilization of its incidence ${ }^{(1)}$. In developing countries, such as Brazil, there is an increase in incidence and prevalence in young adults, adolescents and children; when comparing the two diseases, ulcerative colitis (UC) seems to be more common in preschool children, while $\mathrm{CD}$ is more prevalent in older children ${ }^{(1)}$.

The largest epidemiological study ever carried out on national data, in which more than 210,000 patients were analyzed, revealed an increase in the prevalence of both IBD, but the increase in incidence was only observed in UC, and in the same way there was a predominance of UC when compared to Crohn's disease (CD) ${ }^{(2)}$. These data differ from other national studies, in which there is a predominance of $\mathrm{CD}$ in relation to $\mathrm{UC}$, as in one of the articles in this issue ${ }^{(3)}$, which was carried out in a reference center for IBD in the city of Campinas (São Paulo). The authors emphasize that the increase in incidence and prevalence rates is more evident in recently industrialized countries, specifically in Asia, Africa, Eastern Europe and Latin America. They observed that the patients were young, with no gender predominance, and that there was a higher frequency of patients with $\mathrm{CD}(66.6 \%)$. Most of them $(85.4 \%)$ were undergoing pharmacological treatment and a significant percentage of patients with CD had undergone surgery. This fact might be explained, in part, by the greater complexity of $\mathrm{CD}$, its management and, consequently, the more frequent referral to reference centers, when compared to UC.

Also, regarding epidemiology, the article reinforces the increase of incidence in the young population in parallel with global data on the increase in the pediatric and adolescent populations, possible causes can be attributed to genetic, hygienic, dietary, environmental facts; intestinal microbiota and other causes. The impact on quality of life, school absenteeism, emotional development is evident in all these populations.

These data are shown in another article in this issue ${ }^{(4)}$, specifically in adolescents and young adults in yet another reference center for IBD in Brazil, in the city of São Paulo. In conclusion, the authors observed that adolescents and young adults with IBD activity reported low quality of life related to health at school and at work and in the general health perception domains, which highlights a criterion of disability in these vulnerable populations.

Also in the pediatric population, another article in this issue ${ }^{(5)}$ analyzes the classic serological markers in pediatric inflammatory bowel disease in Brazil in a multicenter study. Its conclusions were that in pediatric patients with IBD in São Paulo, Brazil, serological tests were highly specific, although not very sensitive, for the diagnosis of IBD. However, serological markers were positively correlated to disease severity. In this scenario, the development and search for diagnostic, prognostic and therapeutic markers, play an extremely important role in IBD.

This subject has also been studied and published in another issue of this magazine. Neto et al. ${ }^{(6)}$ performed the metabolic analysis on stool samples from patients with IBD to perform a differential diagnosis between $\mathrm{CD}$ and $\mathrm{UC}$, through the analysis of stool metabolomics by high resolution nuclear magnetic resonance (HI-NMR). They concluded that there was a difference in the metabolomic profile in feces between volunteers and patients

* Universidade Estadual Paulista, Botucatu, SP, Brasil. ORCID: 0000-0002-8166-0304. 
with IBD, being possible to discriminate between patients with $\mathrm{CD}$ and those with UC. Metabolomic analysis is a promising new technique for the recognition and surveillance of patients with IBD. This technique may be useful for diagnosis in adults, but also in the pediatric population, whose diagnosis at an early stage may be more difficult.

Thus, we observe that over the years, Archives of Gastroenterology has been the journal of choice for the publication of articles related to IBD, whether by Brazilian or international authors (Portugal, Argentina, Chile, China and the United Kingdom).
Analyzing the number of publications in IBD between 2013 and 2018, there was an annual average of 5.2 articles/year, and from 2019 to 2020 this average practically multiplied, reaching 10.5/year. I believe that this growth is due to the quality of its editorial board and publications, growing impact factor, indexation, and the fact that it became the official journal of publications of the Brazilian Organization of Crohn and colitis (GEDIIB) with other scientific societies in the field of gastroenterology.

Rogerio SAAD-HOSSNE

\section{REFERENCES}

1. Ng SC, Shi HY, Hamidi N, Underwood FE, Tang W, Benchimol EI, et al. Worldwide incidence and prevalence of inflammatory bowel disease in the 21st century: a systematic review of population-based studies. Lancet. 2018;390:2769-78.

2. Quaresma AB, Damiao AOMC, Coy CSR, Magro DO, Valverde DA, et al. Poster Session 5 - Recent advances in epidemiology DOP41 Temporal trends in epidemiology of IBD in the public healthcare system in Brazil. Journal of Crohn's and Colitis. 2021;15:S079-S080. doi.org/10.1093/ecco-jcc/jjab073.080.

3. Fucilini LMP, Genaro LM, Sousa DC, Coy CSR, Leal RF, Ayrizono MLS. Epidemiological profile and clinical characteristics of inflammatory bowel diseases in a Brazilian referral center. Arq Gastroenterol. 2021;58:483-90.
4. Oba J, Sobrado C, Damião A, Azevedo M, Carlos A, Queiroz N, et al. Health-related quality of life in adolescents and young adults with inflammatory bowel disease is associated with reduction in school and work productivity rather than physical impairment: a multidisciplinary study. Arq Gastroenterol. 2021;58:541-7.

5. Rodrigues M, Bueno C, Lomazi EA, Fernandes MIM, Neufeld CB, D'Amico MFM, Patino MF. Classical serological markers in pediatric inflammatory bowel disease in Brazil. Arq Gastroenterol. 2021;58:495-503.

6. Lins Neto MÁF, Verdi GMX, Veras AO, Veras MO, Caetano LC, Ursulino JS. Use of metabolomics to the diagnosis of inflammatory bowel disease. Arq Gastroenterol. 2020;57:311-5. 